\title{
Infecções comunitárias do trato urinário em Divinópolis, MG: avaliação do perfil de resistência bacteriana e do manejo clínico
}

\author{
Community-acquired urinary tract infections in Divinópolis, Brazil: assesment of bacterial \\ resistance profile and clinical management
}
Infecciones del tracto urinário adquiridas en la comunidad en Divinópolis, Brasil: evaluación del perfil de la resistencia bacteriana y la gestión clínica

Vanessa Machado Ferreiraa ${ }^{a}$, Lucas Nicolas Viana Rossitera, Nicole Faraje Ferreira Aragãoa ${ }^{a}$ Otávio Augusto Pintoa, Paola Mara Santos ${ }^{a}$, Pedro Henrique Alves Cardoso ${ }^{a}$, Thaís Braga Cerqueira ${ }^{a}$, Débora Moura Fernandinoa ${ }^{a}$ Gustavo Machado Rocha ${ }^{a}$

\section{Resumo}

Objetivo: Analisar o perfil de resistência bacteriana e o manejo clínico das infecções do trato urinário (ITU) no município de Divinópolis, MG. Métodos: Trata-se de estudo transversal descritivo, cujos dados foram obtidos a partir das uroculturas positivas realizadas no primeiro semestre de 2015 no Laboratório Municipal de Microbiologia e por meio de entrevistas com médicos atuantes na atenção básica de Divinópolis, MG. Resultados: Das uroculturas avaliadas $(\mathrm{N}=802), 72,8 \%$ isolaram a bactéria Escherichia coli, sendo $38,6 \%$ delas resistentes ao sulfametoxazol+trimetoprima, 33,0\% ao norfloxacino, 31,8\% ao ciprofloxacino e 9,0\% à nitrofurantoína. Dos 57 médicos entrevistados, 73,5\% solicitam, habitualmente, algum exame laboratorial para cistite aguda não complicada. Os antimicrobianos de primeira escolha no tratamento empírico das ITU, segundo os entrevistados, foram norfloxacino $(56,1 \%)$, sulfametoxazol+trimetoprima $(19,3 \%)$, ciprofloxacino $(10,5 \%)$ e nitrofurantoína $(8,8 \%)$. Conclusão: Os dados encontrados indicam que as taxas de resistência bacteriana às quinolonas nas ITU são elevadas e que a terapia empírica adotada pela maioria dos médicos entrevistados vai contra esse perfil de resistência. Por outro lado, foi encontrada uma baixa resistência à nitrofurantoína, demonstrando a necessidade de elaboração de protocolo local de tratamento.

\section{Palavras-chave:}

Escherichia coli

Resistência Microbiana a Medicamentos Atenção Primária de Saúde Uso Racional de Medicamentos

\begin{abstract}
Objective: To analyze the bacterial resistance profile and clinical management of urinary tract infections (UTI) in the city of Divinópolis, Brazil. Methods: This is a cross-sectional descriptive study which data were obtained from the positive urine cultures performed in the first half of 2015 in Municipal Laboratory of Microbiology and from interviews with doctors working in the municipal primary care assistance of Divinópolis. Results: Out of the urocultures evaluated $(\mathrm{N}=802), 72.8 \%$ isolated Escherichia coli, $38.6 \%$ of them being resistant to trimethoprim-sulfamethoxazole, $33.0 \%$ to norfloxacin, $31.8 \%$ to ciprofloxacin and $9.0 \%$ to nitrofurantoin. In the total amount of 57 physicians interviewed, $73.5 \%$ usually order laboratory test for acute uncomplicated cystitis. The antimicrobials of first choice in the empirical treatment of UTI, according to the interviewed, were norfloxacin (56.1\%), trimethoprim-sulfamethoxazole (19.3\%), ciprofloxacin $(10.5 \%)$ and nitrofurantoin $(8.8 \%)$. Conclusion: The data obtained indicate that the rates of bacterial resistance to quinolones are high in UTI and that the empirical therapy adopted by the majority of interviewees goes against this resistance profile. On the other hand, a low resistance to nitrofurantoin was found, which demonstrates the need to elaborate a local treatment protocol.
\end{abstract}

\section{Keywords:}

Escherichia coli

Drug Resistance, Microbial

Primary Health Care

Rational Drug Use
Como citar: Ferreira VM, Rossiter LNV, Aragão NFF, Pinto OA, Santos PM, Cardoso PHA, et al. Infecções comunitárias do trato urinário em Divinópolis, MG: avaliação do perfil de resistência bacteriana e do manejo clínico. Rev Bras Med Fam Comunidade. 2017;12(39):1-13. http://dx.doi.org/10.5712/rbmfc12(39)1553

to

$$
\text { colition }
$$

Conflito de interesses:
declaram não haver.

Procedência e revisão por pares: revisado por pares.

Recebido em: 22/06/2017.

Aprovado em: 26/09/2017. 


\section{Resumen}

Objetivo: Analizar el perfil de resistencia bacteriana y el manejo clínico de las infecciones del tracto urinario (ITU) en la ciudad de Divinópolis, Brasil. Métodos: Se trata de un estudio transversal descriptivo. Los datos fueron obtenidos a partir de los cultivos de orina positivos hechos en el primer semestre de 2015 en el Laboratorio Municipal de Microbiología y por entrevistas con los médicos que trabajan en la atención primaria de Divinópolis. Resultados: De los cultivos de orina evaluados ( $\mathrm{N}=802$ ), $72,8 \%$ encontraron la bacteria Escherichia coli y $38,6 \%$ de ellas eran resistentes al sulfametoxazol+trimetoprima, 33,0\% al norfloxacino, 31,8\% al ciprofloxacino y 9,0\% a la nitrofurantoína. De los 57 médicos entrevistados, $73,5 \%$ solicitan en general algún examen de laboratorio para la cistitis aguda no complicada. Los antimicrobianos de primera opción en el tratamiento empírico de las ITU, según los entrevistados, fueron norfloxacino (56,1\%), sulfametoxazol+trimetoprima (19,3\%), ciprofloxacino (10,5\%) y nitrofurantoína (8,8\%). Conclusión: Los datos encontrados indican altas tasas de resistencia bacteriana a las quinolonas en las ITU y la terapia empírica adoptada por la mayoría de los médicos entrevistados va en contra ese perfil de resistencia. Por otro lado, se encontró una baja resistencia a la nitrofurantoína, demostrando la necesidad de elaboración de protocolo local de tratamiento.
Palabras clave:

Escherichia coli

Farmacorresistencia

Microbiana

Atención Primaria de Salud

Uso Racional de

Medicamentos

\section{Introdução}

As infecções do trato urinário (ITU) são comuns na prática médica e acometem todas as faixas etárias, sendo mais prevalentes em mulheres jovens com vida sexual ativa e em indivíduos com mais de 60 anos. $^{1-4}$ Nos EUA, essas infecções são responsáveis por 8,3 milhões de visitas médicas anualmente e correspondem ao segundo sítio mais comum de infecção na população em geral. ${ }^{5}$ No Brasil, $30 \%$ das mulheres apresentam ao menos um episódio de ITU sintomática ao longo da vida. ${ }^{1,5}$

As ITU são definidas como a invasão microbiana de qualquer órgão do trato urinário, desde a uretra até os rins, podendo ser classificadas em altas (pielonefrite e ureterite) ou baixas (cistite e uretrite). ${ }^{1,2}$ Os fatores de risco associados às ITU são: estase urinária, refluxo vesico-uretral, uso de cateteres urinários (sondas), gravidez, diabetes, relações sexuais desprotegidas, uso de diafragma, prostatismo, idade avançada e transplante renal. ${ }^{4} \mathrm{O}$ diagnóstico é predominantemente clínico, com quadro sugestivo de disúria, polaciúria, urgência miccional, dor suprapúbica e/ou nictúria. ${ }^{5}$

As ITU são causadas mais frequentemente por bactérias Gram-negativas, sendo as principais delas pertencentes à família das Enterobacteriaceae. ${ }^{6}$ Vários estudos realizados no Brasil, entre 2001 e 2011 , bem como Diretrizes da Sociedade Brasileira de Urologia, mostraram Escherichia coli, Proteus spp., Klebsiella pneumoniae, Staphylococcus saprophyticus e Enterococcus faecalis como os principais agentes etiológicos das infecções urinárias, sendo E. coli responsável pela maior proporção, seja em ambiente hospitalar ou na comunidade. , $, 4,7-12^{2}$

Os antimicrobianos melhoraram significativamente a qualidade de vida das populações ao possibilitar o controle de diversas doenças infecciosas, porém seu uso intensificado tem possibilitado um aumento da resistência bacteriana. Inúmeros estudos demonstraram que a principal causa de resistência e seleção de micro-organismos é derivada do uso abusivo e indiscriminado de antimicrobianos. ${ }^{13-15}$ Além do risco de potenciais reações adversas individuais, esse uso inadequado pode levar à ocorrência de efeitos ecológicos adversos, que vão desde a seleção de bactérias resistentes até a colonização e infecção por organismos multirresistentes. ${ }^{15}$

Os tratamentos empíricos para as ITU não complicadas são usados em ambientes extra-hospitalares com recomendações específicas em pacientes sintomáticos, na maioria das vezes, sem a necessidade de realização prévia de urocultura, obtendo-se, dessa forma, maior custo-efetividade. ${ }^{16}$ 
No Brasil, as principais opções de antimicrobianos disponíveis para o tratamento empírico das ITU adquiridas na comunidade, em adultos, são: sulfametoxazol+trimetoprima, norfloxacino, ciprofloxacino, nitrofurantoína, cefalexina, ampicilina e amoxicilina+clavulanato. ${ }^{17}$ Esses tratamentos, no entanto, devem ser guiados por uma sistemática análise do perfil de susceptibilidade e resistência das principais bactérias envolvidas especificamente na comunidade onde ocorrem, diante dos vários antimicrobianos comumente utilizados. ${ }^{16}$

A tendência ao uso indiscriminado de antimicrobianos mais potentes e com espectro mais ampliado tem levado ao aumento das taxas de resistência dos diversos patógenos a esses fármacos. ${ }^{16,18-26}$ Nesse sentido, algumas diretrizes terapêuticas têm sugerido a escolha de determinados antimicrobianos não apenas pela sua potência e eficácia clínica, mas também pelo seu potencial de causar ou não efeitos ecológicos indesejáveis. ${ }^{15}$ Adicionalmente, outros autores têm recomendado evitar o uso de fluoroquinolonas (e.g., norfloxacino, ciprofloxacino) para o tratamento das ITU não complicadas, na medida em que esta classe está comprovadamente associada ao aumento da resistência bacteriana. ${ }^{20,26}$

Um estudo realizado na França avaliou o uso das fluoroquinolonas após divulgação de uma diretriz que orientava a substituição desses fármacos por antimicrobianos de espectro mais restrito. Após 20 meses da implantação da diretriz, observou-se um aumento de $28,5 \%$ no uso de fosfomicina-trometamol, e de $36,8 \%$ no uso de nitrofurantoína. Além disso, houve uma queda de 9,1\% na prescrição de norfloxacino, comprovando o impacto moderado que as diretrizes exercem no exercício e prescrição do médico. ${ }^{27}$

Diante do exposto, há a necessidade de análises locais do perfil de resistência desses micro-organismos, a fim de tornar a conduta profissional e a abordagem terapêutica empírica mais eficientes, de modo a tratar efetivamente as ITU e a prevenir a seleção e a ocorrência de infecções por bactérias resistentes. Dessa forma, este trabalho teve como objetivo avaliar o perfil de resistência bacteriana e o manejo clínico das ITU comunitárias no município de Divinópolis, MG.

\section{Materiais e Métodos}

Trata-se de estudo realizado no município de Divinópolis, MG, do tipo transversal descritivo, que objetivou analisar o padrão de resistência bacteriana das cepas de uropatógenos isoladas de pacientes provenientes da comunidade. Paralelamente, objetivou-se avaliar o manejo clínico das ITU comunitárias por parte dos médicos atuantes na Atenção Primária à Saúde do município. A coleta dos dados foi realizada em duas etapas: 1) Análise dos resultados de uroculturas realizadas no laboratório municipal de análises clínicas do município de Divinópolis, MG; e 2) Entrevistas com médicos atuantes na Atenção Básica do município de Divinópolis, MG.

Na primeira etapa, foram utilizados os arquivos do Centro Municipal de Apoio à Saúde (CEMAS). Trata-se de laboratório público municipal com capacidade técnica de 40 profissionais de diversas áreas, responsável por realizar exames bioquímicos, hematológicos, parasitológicos, hormonais, uroanalíticos, microbiológicos e citológicos.

Cabe ressaltar que o CEMAS processa amostras oriundas de pacientes ambulatoriais do município, sendo que exames de pacientes internados são processados em laboratórios próprios dos hospitais. Só em 2015, foram realizados 597.137 exames, atendendo uma média de 350 a 400 pessoas por dia ${ }^{28}$. 
Deste arquivo, por meio de formulário padronizado, foram coletadas todas as uroculturas com resultados positivos realizadas de janeiro a junho de 2015. Este período foi selecionado por prover dados atualizados e volume significativo. No formulário, levou-se em consideração as datas da coleta de material para exame e do seu resultado; o gênero e a espécie do micro-organismo responsável pela infecção; e a resistência do micro-organismo encontrado aos antimicrobianos testados; e excluindo-se aquelas que não tinham identificação de gênero do micro-organismo.

O teste de sensibilidade do serviço em questão segue os padrões estabelecidos pela Clinical and Laboratory Standards Institute (CLSI) para o exame de sensibilidade antimicrobiana. ${ }^{29}$ Conhecido como método de Kirby-Bauer, se dá a partir da inoculação da amostra coletada de urina em ágar de MuellerHinton e, em caso de crescimento de colônias, o patógeno é identificado e podendo-se suceder ao teste antimicrobiano em si. Sobre a colônia proveniente da urina, são colocados discos de papel impregnados com antimicrobianos em concentrações pré-determinadas.

No laboratório avaliado, são utilizados discos padronizados, com diferentes antimicrobianos, que variam de acordo com a classificação das bactérias em Gram-negativas e Gram-positivas. Para as primeiras, são testados os seguintes antimicrobianos: ácido nalidíxico; amicacina; amoxicilina+clavulanato; ampicilina; cefalotina; cefazolina; cefepime; ceftriaxona; ciprofloxacino; gentamicina; nitrofurantoína; norfloxacino; ofloxacino; sulfametoxazol+ trimetoprima e tetraciclina.

Já para as bactérias Gram-positivas, a bateria inclui a testagem dos antimicrobianos: amoxicilina +clavulanato; ampicilina; cefalotina; ciprofloxacino; clindamicina; cloranfenicol; eritromicina; gentamicina; oxacilina; cefoxitina; benzilpenicilina; rifampicina; sulfametoxazol+trimetoprima; tetraciclina e vancomicina. O diâmetro do halo formado ao redor dos discos, que evidencia a inibição do crescimento ou morte de micro-organismos, indica o grau de susceptibilidade deles ao antimicrobiano impregnado no papel. ${ }^{29}$

Na segunda etapa, foram convidados a participar do estudo os médicos atuantes na rede de atenção primária do município de Divinópolis, MG, seja em Unidades Básicas de Saúde (UBS) ou Estratégia Saúde da Família (ESF). O município é polo da Região Ampliada de Saúde Centro-Oeste de Minas Gerais, que tem população estimada de 232.945 pessoas, ${ }^{30}$ contando com 47 estabelecimentos de saúde SUS, atualmente com 43 unidades de Atenção Primária à Saúde, sendo 11 unidades tradicionais e 32 Estratégias de Saúde da Família.

Os médicos que atuavam exclusivamente na assistência pediátrica foram excluídos. Isto por tratar-se de um estudo sobre as infecções adquiridas na comunidade e, portanto, comumente tratadas nesses locais de assistência. Após assinatura de Termo de Consentimento Livre e Esclarecido (TCLE), os profissionais que aceitaram participar da pesquisa responderam a uma entrevista face a face por meio de questionário semiestruturado, cujo principal objetivo foi avaliar o manejo clínico das principais infecções urinárias comunitárias, com foco na cistite aguda não complicada.

O questionário foi dividido em três eixos: dados sociodemográficos e formação médica (naturalidade; residência e domicílio do médico; instituição de ensino de formação acadêmica; ano de conclusão da graduação; e se realizou pós-graduação, residência médica e/ou curso de especialização), diagnóstico de cistite aguda não complicada (propedêutica e exames complementares solicitados) e tratamento de cistite aguda não complicada (medicamentos prescritos e respectivas posologias; duração do tratamento; e acompanhamento). 
Foi realizada análise descritiva dos dados, com distribuição de proporções para as variáveis categóricas e medidas de tendência central para as variáveis contínuas, incluindo intervalo de confiança de $95 \%$. A análise e o gerenciamento do banco de dados foram feitos com a utilização do software Epi Info ${ }^{\circledR}$ (Centers for Disease Control and Prevention, Atlanta, USA).

Este projeto foi aprovado pelo Comitê de Ética em Pesquisa Envolvendo Seres Humanos do Campus Centro-Oeste Dona Lindu da Universidade Federal de São João del-Rei, Divinópolis, MG, com o número do parecer 1.100.148 de 10 de junho 2015, bem como pela Secretaria Municipal de Saúde de Divinópolis, MG.

\section{Resultados}

Entre 1 de janeiro e 30 de junho de 2015, foram realizadas 3995 uroculturas no laboratório municipal de Divinópolis, MG, sendo 802 (20,1\%) positivas. Em relação aos agentes etiológicos identificados (Tabela 1), $72,8 \%$ das amostras isolaram a bactéria Escherichia coli. Outras bactérias encontradas foram Klebsiella sp. (13,1\%), Proteus sp. (5,4\%), Staphylococcus sp. (2,8\%) e Pseudomonas sp. (1,5\%).

Tabela 1. Perfil de resistência das bactérias mais frequentes aos principais antimicrobianos testados no estudo. Divinópolis, $M G, 2015$. ( $N=802)$.

\begin{tabular}{|c|c|c|c|c|}
\hline Antimicrobiano & \multicolumn{3}{|c|}{ \% resistência' } & Total" ( $\mathrm{N}=802)$ \\
\hline Sulfametoxazol+Trimetoprima & 38,6 & 24,8 & 45,0 & 37,6 \\
\hline Ciprofloxacino & 31,8 & 29,5 & 25,6 & 31,1 \\
\hline Nitrofurantoína & 9,0 & 65,7 & 90,5 & 22,5 \\
\hline Cefepime & 9,8 & 11,2 & 23,8 & 11,1 \\
\hline Gentamicina & 19,2 & 19,4 & 18,6 & 19,6 \\
\hline Ceftriaxona & 10,1 & 13,5 & 26,8 & 11,9 \\
\hline Amoxicilina+Clavulanato & 16,0 & 21,3 & 21,9 & 18,3 \\
\hline Ampicilina & 49,7 & 84,3 & 58,1 & 55,8 \\
\hline
\end{tabular}

' Porcentagem de uroculturas resistentes excluindo informações ignoradas; " Incluindo todas as bactérias isoladas (além das 3 principais discriminadas).

Foram realizadas 697 uroculturas provenientes de pacientes do sexo feminino. Dessas, 53 eram de pacientes com até 18 anos, com a seguinte distribuição: 66,0\% E. coli, 9,4\% Klebsiella sp., 9,4\% Staphylococcus sp., 7,6\% Proteus sp., 1,9\% Pseudomonas sp. e 5,7\% outras. Desse total, 18 uroculturas são de pacientes até 12 anos e 35 de pacientes entre 13 e 18 anos. A faixa etária com maior número de exames no sexo feminino foi de entre 19 a 60 anos, totalizando 432 exames, sendo $75,5 \%$ de E. coli, 11,81\% Klebsiella sp., 3,9\% Proteus sp., 3,2\% Staphylococcus sp., 1,2\% Pseudomonas sp., 0,2\% Enterobacter sp., 3,9\% outras e 0,2\% foi ignorada. Acima de 60 anos foram realizados 212 exames, sendo que 76,4\% isolaram E. coli, 10,8\% Klebsiella sp., 7,1\% Proteus sp., 1,4\% Pseudomonas sp., 0,5\% Staphylococcus sp., $2,8 \%$ outras e $0,9 \%$ foi ignorada.

Outras 104 uroculturas eram provenientes de pacientes do sexo masculino, 18 em pacientes até 18 anos. Nesse grupo, 62,5\% das uroculturas isolaram E. coli e 37,5\% isolaram Proteus sp. De 19 a 60 
anos, sexo masculino, foram realizados 29 exames, sendo 58,6\% de E. coli, 34,5\% Klebsiella sp., 3,5\% Pseudomonas sp. e 3,5\% outras. O pico de exames no sexo masculino foi nos maiores de 60 anos, totalizando 67 exames. Destes, 56,7\% eram de E. coli, 23,9\% Klebsiella sp., 6,0\% Proteus sp., 3,0\% Pseudomonas sp., 3,0\% Staphylococcus sp. e 7,5\% outras.

Analisando o perfil de resistência da Escherichia coli $(\mathrm{N}=584), 38,6 \%$ das amostras testadas eram resistentes ao sulfametoxazol+trimetoprima, 33,0\% ao norfloxacino, 31,8\% ao ciprofloxacino e apenas 9,0\% à nitrofurantoína. Já quando se observa o perfil de resistência geral, incluindo todas as espécies isoladas, $37,6 \%$ eram resistentes ao sulfametoxazol+trimetoprima, $32,1 \%$ ao norfloxacino, $31,1 \%$ ao ciprofloxacino e $22,5 \%$ à nitrofurantoína. A menor taxa de resistência geral foi à amicacina (10\%) (Tabela 1).

Dentre os médicos atuantes na Atenção Básica do município, 18 (23,4\%) não foram abordados (encontravam-se de férias ou licença durante o período de recrutamento) e 2 (2,6\%) médicos recusaramse a participar da pesquisa, sendo que 57 (74,0\%) responderam ao questionário. Destes, 34 (59,7\%) eram do sexo masculino, com variação da idade entre 28 e 69 anos (mediana $=42$ anos). Já o tempo de experiência na profissão médica variou de 1 a 43 anos (mediana = 19 anos).

Do total de médicos, 28 (49,1\%) eram brasileiros e 29 (50,9\%) eram cubanos, sendo que $31(54,4 \%)$ possuíam especialização ou residência médica concluída em Medicina de Família e Comunidade (cinco brasileiros e 26 estrangeiros) e 29 (50,9\%) informaram possuir outra especialização ou residência médica concluída (19 brasileiros e 10 estrangeiros). Quando questionados se possuíam alguma residência médica ou especialização em curso, 7 brasileiros $(25,0 \%)$ responderam de forma afirmativa, sendo $3(42,8 \%)$ em Medicina de Família e Comunidade. Dentre os estrangeiros, 23 (79,3\%) responderam que estavam cursando especialização em Saúde da Família.

Quanto ao manejo das ITU, 42 (73,5\%) médicos revelaram que solicitam, de forma habitual, algum exame laboratorial diante de um paciente com suspeita de cistite aguda não complicada. Destes, 71,9\% utilizam, na propedêutica habitual, o exame de urina rotina, 52,6\% o Gram de gota não centrifugada, 26,3\% a urocultura, $21,0 \%$ o hemograma e 3,5\% a dosagem sérica de Proteína $\mathrm{C}$ reativa (Tabela 2).

Quando perguntados sobre as indicações de realização de urocultura previamente ao início do tratamento antimicrobiano, $61,4 \%$ dos médicos disseram que solicitariam urocultura em casos de ITU de repetição; $24,5 \%$ caso o paciente fosse portador de outra comorbidade; $12,2 \%$ nos casos de falha terapêutica; 12,2\% em todos os pacientes com suspeita de ITU e 4 (7,0\%) entrevistados não solicitariam urocultura prévia em nenhuma situação (Tabela 2).

Em relação ao antimicrobiano de primeira escolha no tratamento empírico de uma cistite aguda não complicada no adulto, a maioria dos médicos optou por norfloxacino $(56,1 \%)$, seguido por sulfametoxazol+trimetoprima (19,3\%), ciprofloxacino (10,5\%) e nitrofurantoína (8,8\%) (Tabela 2). A duração do tratamento para o antimicrobiano escolhido foi de 3 dias para 3,5\% dos entrevistados, 5 dias para 10,5\% deles, 7 dias para $68,4 \%$ e 10 dias para $17,5 \%$.

Entre as possíveis opções terapêuticas para o tratamento empírico de cistite aguda não complicada em adultos, a maioria dos entrevistados respondeu que poderia utilizar norfloxacino $(93,0 \%)$, sulfametoxazol+trimetoprima ( $86,0 \%)$, ciprofloxacino $(84,2 \%)$ ou nitrofurantoína $(84,2 \%)$. Adicionalmente, os antimicrobianos cefalexina, amoxicilina e ampicilina foram considerados como possíveis opções terapêuticas por $54,4 \%, 40,3 \%$ e $28,1 \%$ dos médicos entrevistados, respectivamente (Tabela 2 ). 
Tabela 2. Manejo clínico dos médicos atuantes na Atenção Primária a Saúde em Divinópolis, MG, 2015. (N=57).

\begin{tabular}{|c|c|c|}
\hline Manejo clínico de ITU (cistite aguda não complicada) & $\mathbf{N}^{\prime}$ & $\% "$ \\
\hline \multicolumn{3}{|l|}{ Exames laboratoriais habitualmente solicitados } \\
\hline Urina rotina & 41 & $71,9 \%$ \\
\hline Gram de gota & 30 & $52,6 \%$ \\
\hline Urocultura & 15 & $26,3 \%$ \\
\hline Hemograma & 12 & $21,0 \%$ \\
\hline Proteína C reativa & 2 & $3,5 \%$ \\
\hline \multicolumn{3}{|c|}{$\begin{array}{l}\text { Situações nas quais indicariam a realização da urocultura previamente } \\
\text { ao início do tratamento antimicrobiano }\end{array}$} \\
\hline ITU de repetição & 35 & $61,4 \%$ \\
\hline Comorbidade & 14 & $24,5 \%$ \\
\hline Falha terapêutica & 7 & $12,2 \%$ \\
\hline Todos com suspeita de ITU & 7 & $12,2 \%$ \\
\hline \multicolumn{3}{|l|}{ Antimicrobiano de primeira escolha no tratamento empírico } \\
\hline Norfloxacino & 32 & $56,1 \%$ \\
\hline Sulfametoxazol+trimetoprima & 11 & $19,3 \%$ \\
\hline Ciprofloxacino & 6 & $10,5 \%$ \\
\hline Nitrofurantoína & 5 & $8,8 \%$ \\
\hline Outro & 3 & $5,3 \%$ \\
\hline \multicolumn{3}{|c|}{ Duração habitual indicada para o tratamento antimicrobiano (dias) } \\
\hline 3 dias & 2 & $3,5 \%$ \\
\hline 5 dias & 6 & $10,5 \%$ \\
\hline 7 dias & 39 & $68,4 \%$ \\
\hline 10 dias & 10 & $17,6 \%$ \\
\hline
\end{tabular}

' Número absoluto de médicos que responderam determinada variável; " Excluindo informações ignoradas; ITU: Infecção do trato urinário.

\section{Discussão}

\section{Resumo dos principais achados}

Os dados apresentados mostram que são elevadas as taxas de resistência aos principais antimicrobianos (sulfametoxazol+trimetoprima, norfloxacino e ciprofloxacino) habitualmente utilizados para o tratamento de ITU no município de Divinópolis, MG. A maioria das amostras analisadas era proveniente de pacientes do sexo feminino, sendo o principal agente etiológico a bactéria $E$. coli, achados semelhantes aos outros estudos sobre o assunto. ${ }^{2,10,18,24,25}$

A taxa de resistência encontrada para $E$. coli aos antimicrobianos comumente utilizados na prática clínica foi elevada, sendo de 38,6\% para sulfametoxazol+trimetoprima, 33,0\% para norfloxacino e 32,0\% para ciprofloxacino. Por outro lado, a resistência das cepas isoladas de $E$. coli à nitrofurantoína foi a mais baixa $(9,0 \%)$ dentre os antimicrobianos disponíveis para uso ambulatorial.

Em relação ao manejo clínico da cistite aguda não complicada em adultos, a maioria dos médicos entrevistados afirmou solicitar, habitualmente, algum exame para confirmação do diagnóstico, indo de encontro às principais diretrizes atuais, ${ }^{15}$ que recomendam o tratamento empírico das ITU não complicadas, considerando que a $E$. coli é a principal bactéria responsável pelas ITU não complicadas em todo o mundo., 2,4,7,12,15 
Desta forma, é possível selecionar previamente os antimicrobianos adequados para a maioria da população, considerando-se apenas especificidades locais de resistência dos uropatógenos, ${ }^{15}$ não sendo necessária, na maioria dos casos, a realização de exames complementares para diagnóstico etiológico. Além disso, de uma maneira geral e conforme demonstrado no presente estudo, a nitrofurantoína apresenta boa atividade in vitro contra as principais bactérias causadoras de ITU não complicada, podendo ser recomendada como antimicrobiano de primeira escolha para tratamento empírico das ITU, ${ }^{15}$ muito embora seja muito pouco priorizada como primeira escolha nesses casos, considerando o município estudado.

Cabe destacar que a amostra de profissionais participantes deste estudo foi composta por médicos generalistas brasileiros e estrangeiros, estes vinculados ao Programa Mais Médicos para o Brasil. ${ }^{31}$ Conforme demonstrado, de uma maneira geral, apesar de os médicos participantes possuírem ampla experiência profissional (mediana=19 anos de experiência) e formação em nível de pós-graduação (54,4\% com residência ou especialização concluída em Medicina de Família e Comunidade), os resultados apresentados demonstram uma evidente necessidade de educação continuada direcionada a esses profissionais, considerando o manejo clínico geral dessas infecções (principais antimicrobianos utilizados, tempo de tratamento e solicitação de propedêutica urinária).

Fortalezas e limitações do estudo

Este trabalho avaliou a totalidade das amostras de uroculturas realizadas no período estudado $(\mathrm{N}=802)$, sendo possível, dessa forma, descrever um perfil epidemiológico representativo das bactérias causadoras de ITU no município. Outro ponto forte deste estudo é o potencial de gerar mudança imediata de manejo e impacto positivo na prática clínica dos profissionais da saúde, por meio da elaboração de protocolo local para tratamento das ITU comunitárias, melhorando a assistência médica da população atendida na Atenção Primária à Saúde e proporcionando a formação continuada dos profissionais de saúde do município.

As limitações deste estudo foram a impossibilidade de diferenciação de eventuais bactérias adquiridas em ambiente hospitalar, porém diagnosticadas como comunitárias após alta recente, ou mesmo bactérias provenientes de pacientes com ITU de repetição. Neste sentido, é possível que haja uma superestimação da proporção de bactérias resistentes. Além disso, houve um alto percentual de perda amostral de médicos elegíveis. Embora haja essas limitações, os resultados mostram um evidente uso indiscriminado e por tempo excessivo de fluoroquinolonas pelos médicos, além de uma alta taxa de resistência dos principais agentes etiológicos das ITU comunitárias a esses antimicrobianos.

Comparação com a literatura já existente

Os resultados apresentados evidenciam claramente altas taxas de resistência às quinolonas nas ITU comunitárias e reafirmam a necessidade de estudos locais do perfil de resistência, a fim de orientar o tratamento empírico adequado dessas infecções. Os agentes etiológicos encontrados foram semelhantes a um estudo brasileiro, o qual isolou E. coli, Klebsiella spp. e Staphylococcus sp. em $82 \%$ das amostras. ${ }^{32}$

A maioria das amostras no estudo supracitado foi sensível à nitrofurantoína (>92\%) e altas taxas de resistência bacteriana ao sulfametoxazol+trimetoprima e às quinolonas também foram observadas. ${ }^{32}$ 
Uma revisão sistemática de estudos observacionais publicados entre 2004 e 2014 incluiu 51 trabalhos que analisaram o perfil de resistência de ITU adquirida na comunidade. A taxa geral de resistência da $E$. coli ao ciprofloxacino nessa análise foi de $27,0 \%,{ }^{33}$ com tendência de aumento dessa resistência com o tempo, sendo as maiores taxas nos países em desenvolvimento. ${ }^{33}$

Uma análise realizada na Bavária, Alemanha, mostrou o aumento da resistência da $E$. coli ao ciprofloxacino de 5,0\% em 2000 para 10,0\% em 2006. ${ }^{20}$ Nesse mesmo estudo, foi observada uma correlação positiva entre o uso de ciprofloxacino e a proporção de $E$. coli resistente ao sulfametoxazol+trimetoprima. ${ }^{20}$ Outro estudo semelhante realizado nos EUA observou o crescimento da resistência de E. coli ao ciprofloxacino de 3\% para $17 \%$ entre 2000 e $2010 .{ }^{21}$ Esses autores associam o alto índice do uso de fluoroquinolonas com o aumento de novas cepas de $E$. Coli resistentes a essa classe de antimicrobianos.

Uma pesquisa recente conduzida no Brasil identificou os agentes etiológicos mais prevalentes nas ITU adquiridas na comunidade e descreveu o perfil de resistência em relação ao ciprofloxacino. A taxa de resistência geral das bactérias a esse antimicrobiano foi de 18,4\% (36\% dentre as amostras de E. coli). ${ }^{34}$ Adicionalmente, na região do Triângulo Mineiro, foram avaliadas as uroculturas positivas para E. coli de janeiro de 2010 a dezembro de 2015, cujos resultados mostraram $29,0 \%$ de resistência ao ciprofloxacino, 31,0\% ao norfloxacino e somente 6,0\% à nitrofurantoína. ${ }^{35}$ Em São Luís, Maranhão, foram analisadas 875 uroculturas provenientes de ITU comunitárias, com 45,0\% de resistência da E. coli ao sulfametoxazol+trimetoprima. ${ }^{24}$

Em análise na Turquia, os pesquisadores encontraram 35,0\% de resistência de E. Coli ao sulfametoxazol+trimetoprima e $26,0 \%$ ao ciprofloxacino, com apenas $2,0 \%$ das amostras resistentes à fosfomicina. ${ }^{36}$ Adicionalmente, um estudo francês encontrou $38,0 \%$ de resistência de $E$. coli à amoxicilina, ${ }^{37}$ o que reforça a recomendação de evitar o uso de antimicrobianos beta-lactâmicos no tratamento das ITU comunitárias. ${ }^{15}$

O aumento da resistência bacteriana aos antimicrobianos classicamente usados no tratamento das ITU, como o sulfametoxazol+trimetoprima e os beta-lactâmicos, provocou uma maior prescrição de fluorquinolonas como primeira escolha no tratamento empírico da cistite aguda não complicada. ${ }^{20,24,33-35}$ Conforme demonstrado, o uso indiscriminado desses medicamentos leva ao aumento da resistência bacteriana. Associado à automedicação e à baixa adesão ao tratamento, esses fatores podem ter contribuído para uma maior ocorrência de falha terapêutica e consequências negativas para o paciente e para o sistema de saúde.

Uma meta-análise verificou as implicações da resistência bacteriana na recuperação clínica de pacientes com infecções comuns adquiridas na comunidade. Obteve-se como desfecho primário a falha terapêutica, constatada pela persistência dos sintomas após término do tratamento antimicrobiano. Como resultados, estimou-se que a falha terapêutica nos pacientes tratados para ITU causadas por $E$. coli resistente foi quase três vezes maior do que nos pacientes com ITU por E. coli sensível aos antimicrobianos usados. ${ }^{38}$

Além disso, outros desfechos, como a maior severidade dos sintomas, a maior chance de se reconsultar com um médico e a maior necessidade do uso de outros antimicrobianos foram percebidos no primeiro grupo de pacientes, o que demonstra as consequências negativas da alta resistência bacteriana 
para a saúde dos indivíduos e para o orçamento em saúde pública. ${ }^{38}$ Dentro desse contexto, os estudos locais para conhecimento dos agentes etiológicos mais frequentes nas infecções comunitárias e do perfil de sensibilidade destes se estabelecem como uma importante ferramenta para estimular o uso racional de medicamentos e diminuir os efeitos ecológicos indesejáveis, como o aumento da resistência bacteriana por uso indiscriminado de antimicrobianos.

Implicações para pesquisa na área e/ou para prática profissional

O estudo possibilitou a confecção de material educativo para os médicos atuantes na Atenção Primária à Saúde em Divinópolis, MG, a fim de orientar o manejo adequado das ITU não complicadas, desde o diagnóstico clínico até tratamento empírico mais adequado, tendo como base o perfil de resistência encontrado no município. Nesse material, com base nos resultados apresentados, os autores recomendaram a nitrofurantoína como o antimicrobiano de primeira escolha para o tratamento empírico das ITU comunitárias em Divinópolis, MG, por seu espectro de ação mais reduzido e sua baixa taxa de resistência entre os uropatógenos mais frequentes.

Além disso, reforçaram as recomendações de entidades médicas nacionais e internacionais para o diagnóstico clínico da cistite aguda não complicada, geralmente sendo desnecessária a realização de exame complementar, além da recomendação da redução no tempo médio de tratamento para três a cinco dias nos casos de ITU não complicada. ${ }^{15,39,40}$

Ademais, caso as recomendações de prática clínica colocadas neste artigo sejam adotadas, este trabalho servirá como base para futuras comparações na evolução do perfil de resistência nas ITU comunitárias no município, permitindo também aos gestores de saúde a avaliação do impacto global de medidas de educação permanente dos profissionais e o estímulo à realização de pesquisas locais semelhantes.

\section{Conclusões}

As observações deste estudo permitem concluir que, embora exista uma alta taxa de resistência às quinolonas pelas bactérias causadoras de ITU comunitárias, há uma prescrição abusiva desta classe de antimicrobianos pelos médicos atuantes na atenção básica do município de Divinópolis, MG. Além disso, percebe-se a solicitação abusiva de propedêutica complementar nessas infecções, além de indicação de tempo excessivo de tratamento. Com base nos resultados apresentados, dentre os antimicrobianos testados, a nitrofurantoína apresentou o espectro de ação mais reduzido e uma menor taxa de resistência entre os uropatógenos mais frequentes nas ITU comunitárias em Divinópolis, MG.

Os autores reforçam a recomendação do diagnóstico clínico da cistite aguda não complicada, habitualmente sem a necessidade de realização de exame complementar, e da diminuição do tempo médio de tratamento para três a cinco dias nos casos de ITU não complicada, conforme as recomendações de entidades médicas nacionais e internacionais. ${ }^{15,39,40}$ Neste sentido, recomenda-se a elaboração de estratégia específica de educação envolvendo os médicos atuantes no município, abordando diagnóstico e manejo das ITU comunitárias. 
Diante de um contexto de destaque das quinolonas no tratamento de infecções mais graves, como a pielonefrite e sepse urinária, a crescente resistência bacteriana no tratamento da infecção comunitária alerta para o uso mais criterioso desses medicamentos. Portanto, recomenda-se reservar esses antimicrobianos para casos mais graves ou nos quais haja falha terapêutica com o uso de antimicrobianos de menor espectro de ação e menor taxa de resistência, quando se tratar de ITU não complicadas no município.

\title{
Conflito de interesse
}

\author{
Os autores declaram não haver conflitos de interesse.
}

\section{Referências}

1. Levi CE. Principais síndromes infecciosas: Manual de Microbiologia Clínica para o Controle de Infecção em Serviços de Saúde. Brasília: Agência Nacional de Vigilância Sanitária; 2004. [acesso 2017 Out 10]. Disponível em: http://bvsms.saude.gov.br/bvs/publicacoes/ manual_microbiologia_completo.pdf

2. Pires MCS, Frota KS, Martins Junior PO, Correia AF, Cortez-Escalante JJ, Silveira CA. Prevalência e suscetibilidades bacterianas das infecções comunitárias do trato urinário, em Hospital Universitário de Brasília, no período de 2001 a 2005. Rev Soc Bras Med Trop. 2007;40(6):643-7. [acesso 2017 Out 10]. DOI: http://dx.doi.org/10.1590/S0037-86822007000600009

3. Muller EV, Santos DF, Corrêa NAB. Prevalência de microrganismos em infecções do trato urinário de pacientes atendidos no laboratório de análises clínicas da Universidade Paranaense - Umuarama - PR. Rev Bras Anal Clin. 2008;40(1):35-7. [acesso 2017 Out 10]. Disponíve em: http://bases.bireme.br/cgi-bin/wxislind.exe/iah/online/?IsisScript=iah/iah.xis\&lang=p\&nextAction=Ink\&base=LILACS\&exprSearch= \%22Rev.\%20bras.\%20anal.\%20clin/2008,40(1)\%22\&indexSearch=TA

4. Heilberg IP, Schor N. Abordagem diagnóstica e terapêutica na infecção do trato urinário - Itu. Rev Assoc Med Bras. 2003;49(1):109-16. [acesso 2017 Out 10]. DOI: http://dx.doi.org/10.1590/S0104-42302003000100043

5. Roriz-Filho JS, Vilar FC, Mota LM, Leal CL, Pisi PCB. Infecção do trato urinário. Medicina. 2010;43(2):118-25. [acesso 2017 Out 10]. DOI: http://dx.doi.org/10.11606/issn.2176-7262.v43i2p118-125

6. Murray PR, Rosenthal KS, Pfaller MA. Microbiologia Médica. Rio de Janeiro: Elsevier; 2009.

7. Miranda EJP, Oliveira GSS, Roque FL, Santos SR, OImos RD, Lotufo PA. Susceptibility to antibiotics in urinary tract infections in a secondary care setting from 2005-2006 and 2010-2011, in São Paulo, Brazil: Data from 11,943 urine cultures. Rev Inst Med Trop. 2014;56(4):313-24. [acesso 2017 Out 10]. DOI: http://dx.doi.org/10.1590/S0036-46652014000400009

8. Araujo KL, Queiroz AC. Análise do perfil dos agentes causadores de infecção do trato urinário e dos pacientes portadores, atendidos no Hospital e Maternidade Metropolitano-SP. J Health Sci Inst. 2012;30(1):7-12. [acesso 2017 Out 10]. Disponível em http://189.2.156.229/ comunicacao/publicacoes/ics/edicoes/2012/01_jan-mar/V30_n1_2011_p7-12.pdf

9. Braoios A, Turatti TF, Meredija LCS, Campos TRS, Denadai FHM. Infecções do trato urinário em pacientes não hospitalizados: etiologia e padrão de resistência aos antimicrobianos. J Bras Patol Med Lab.2009;45(6):449-56. [acesso 2017 Out 10]. DOI: http://dx.doi.org/10.1590/ S1676-24442009000600003

10. Correia C, Costa E, Peres A, Alves M, Pombo G, Estevinho L. Etiologia das infecções do tracto urinário e sua susceptibilidade aos antimicrobianos. Acta Med Port.2007;20:543-9. [acesso 2017 Out 10]. Disponível em: https://bibliotecadigital.ipb.pt/bitstream/10198/517/1/ acta\%20medica\%20port.pdf

11. Sacomani CAR, Resplande J, Carvalho M, Dambros M, Simões R, Bernardo WM. Infecção urinária na mulher: Investigação Diagnóstica. Diretrizes da Sociedade Brasileira de Urologia. [acesso 2017 Out 10]. Disponível em: http://portaldaurologia.org.br/publicacoes/diretrizes/

12. Lopes HV, Tavares W. Diagnóstico das infecções do trato urinário. Rev Assoc Med Bras. 2005;51(6):306-8. [acesso 2017 Out 10]. DOI: http://dx.doi.org/10.1590/S0104-42302005000600008

13. Brasil. Ministério da Saúde. Uso Racional de Medicamentos: temas selecionados. Brasília: Ministério da Saúde; 2012 . [acesso 2017 Out 10]. Disponível em: http://bvsms.saude.gov.br/bvs/publicacoes/uso_racional_medicamentos_temas_selecionados.pdf

14. World Health Organization - WHO. Medicines use in primary care in developing and transitional countries: Fact book summarizing results from studies reported between 1990 and 2006. Geneva: World Health Organization; 2009. [acesso 2017 Out 10]. Disponível: em http:// www.who.int/medicines/publications/who_emp_2009.3/en/ 
15. Gupta K, Hooton TM, Naber KG, Wullt B, Colgan R, Miller LG, et al. International clinical practice guidelines for the treatment of acute uncomplicated cystitis and pyelonephritis in women: A 2010 update by the Infectious Diseases Society of America and the European Society for Microbiology and Infectious Diseases. Clin Infect Dis. 2011;52(5):e103-20. [acesso 2017 Out 10]. DOI: http://dx.doi.org/10.1093/ cid/ciq257

16. McEwen LN, Farjo R, Foxman B. Antibiotic prescribing for cystitis: how well does it match published guidelines? Ann Epidemiol. 2003;13(6):479-83. [acesso 2017 Out 10]. DOI: http://dx.doi.org/10.1016/S1047-2797(03)00009-7

17. Koch CR, Ribeiro JC, Schnor OH, Zimmermann BS, Müller FM, D’ Agostin J, et al. Resistência antimicrobiana dos uropatógenos em pacientes ambulatoriais, 2000-2004. Rev Soc Bras Med Trop. 2008;41(3):277-81. [acesso 2017 Out 10]. DOI: http://dx.doi.org/10.1590/ S0037-86822008000300010

18. Soares LA, Nishi CYM, Wagner HL. Isolamento das bactérias causadoras de infecções urinárias e seu perfil de resistência aos antimicrobianos. Rev Bras Med Fam Comunidade. 2006;2(6):84-92. [acesso 2017 Out 10]. DOI: http://dx.doi.org/10.5712/rbmfc2(6)29

19. Kahan E, Kahan NR, Chinitz DP. Urinary tract infection in women-physician's preferences for treatment and adherence to guidelines: a national drug utilization study in a managed care setting. Eur J Clin Pharmacol. 2003;59(8-9):663-8. [acesso 2017 Out 10]. DOI: http:// dx.doi.org/10.1007/s00228-003-0673-4

20. Borgmann S, Jakobiak T, Gruber H, Schröder H, Sagel U. Ciprofloxacin treatment of urinary infections results in increased resistance of urinary E. coli to ciprofloxacin and co-trimoxazole. Pol J Microbiol. 2009;58(4):371-3. [acesso 2017 Out 10]. Disponível em: http://www. pjm.microbiology.pl/archive/vol5842009371.pdf

21. Sanchez GV, Master RN, Karlowsky JA, Bordon JM. In vitro antimicrobial resistance of urinary Escherichia coli isolates among U.S. outpatients from 2000 to 2010. Antimicrob Agents Chemother. 2012;56(4):2181-3. [acesso 2017 Out 10]. DOI: http://dx.doi.org/10.1128/ AAC.06060-11

22. Esmerino LA, Gonçalves LG, Schelesky ME. Perfil de sensibilidade antimicrobiana de cepas Escherichia coli isoladas de infecções urinárias comunitárias. Publ UEPG Ciênc Biol Saúde. 2003;9(1):31-9. [acesso 2017 Out 10]. Disponível em: www.revistas2.uepg.br/ index.php/biologica/article/download/357/365

23. Swei Lo D, Ragazzi SLB, Gilio AE, Martinez MB. Infecção urinária em menores de 15 anos: etiologia e perfil de sensibilidade antimicrobiana em hospital geral de pediatria. Rev Paul Pediatr. 2010;28(4):299-303. [acesso 2017 Out 10]. DOI: http://dx.doi.org/10.1590/S010305822010000400003

24. Santana TCFS, Pereira EMM, Monteiro SG, Carmo MS, Turri RJG, Figueiredo PMS. Prevalência e resistência bacteriana aos agentes antimicrobianos de primeira escolha nas infecções do trato urinário no município de São Luís - MA. Rev Patol Trop. 2012;41(4):409-18. [acesso 2017 Out 10]. DOI: http://dx.doi.org/10.5216/rpt.v41i4.21704

25. Cardoso NS. Avaliação da susceptibilidade de Escherichia coli, isoladas de infecções humanas, aos antimicrobianos usuais [Trabalho de Conclusão de Curso]. Divinópolis: Faculdades Integradas Pitágoras; 2013.

26. Bitencourt JS, Pavanelli MF. Urinary infection in patients of public health care of Campo Mourão-PR, Brazil: bacterial prevalence and sensitivity profile. J Bras Patol Med Lab. 2014;50(5):346-1. [acesso 2017 Out 10]. DOI: http://dx.doi.org/10.5935/1676-2444.20140038

27. Slekovec C, Leroy J, Vernaz-Hegi N, Faller JP, Sekri D, Hoen B, et al. Impact of a region wide antimicrobial stewardship guideline on urinary tract infection prescription patterns. Int J Clin Pharm. 2012;34(2):325-9. [acesso 2017 Out 10]. DOI: http://dx.doi.org/10.1007/ s11096-012-9606-6

28. Prefeitura de Divinópolis. Laboratório amplia exames e reduz espera. 2016. [acesso 2017 Ago 5]. Disponível em: http://www.divinopolis. mg.gov.br/portal/noticias/0/3/3958/Laborat\%C3\%B3rio-amplia-exames-e-diminui-espera

29. Clinical and laboratory Standards Institute. Methods for Dilution Antimicrobial Susceptibility Tests for Bacteria That Grow Aerobically; Approved Standard-Ninth Edition. 2012;32 Suppl 2:M07-A9. [acesso 2017 Out 10]. Disponível em: http://clsi.org/

30. Brasil. Ministério do Planejamento, Orçamento e Gestão. Instituto Brasileiro de Geografia e Estatística. Contagem Populacional. 2010. [acesso 2017 Ago 5]. Disponível em https://cidades.ibge.gov.br/v4/brasil/mg/divinopolis/panorama

31. Brasil. Diário Oficial da União. Lei № 12.871, de 22 de Outubro de 2013. Institui o Programa Mais Médicos, altera as Leis № 8.745, de 9 de dezembro de 1993, e nº 6.932, de 7 de julho de 1981, e dá outras providências. Brasília: Diário Oficial da União; 2013.

32. Cunha MA, Assunção GLM, Medeiros IM, Freitas MR. Antibiotic resistance patterns of urinary tract infections in a northeastern Brazilian capital. Rev Inst Med Trop. 2016;58:2. [acesso 2017 Out 10]. DOI: http://dx.doi.org/10.1590/S1678-9946201658002 
33. Fasugba O, Gardner A, Mitchell BG, Mnatzaganian G. Ciprofloxacin resistance in community- and hospital-acquired Escherichia coli urinary tract infections: a systematic review and meta-analysis of observational studies. BMC Infect Dis. 2015;15:545. [acesso 2017 Out 10]. DOI: http://dx.doi.org/10.1186/s12879-015-1282-4

34. Reis ACC, Santos SRS, Souza SC, Saldanha MG, Pitanga TN, Oliveira RR. Ciprofloxacin resistance pattern among bacteria isolated from patients with community-acquired urinary tract infection. Rev Inst Med Trop. 2016;58:53. [acesso 2017 Out 10]. DOI: http://dx.doi. org/10.1590/S1678-9946201658053

35. Rodrigues WF, Miguel CB, Nogueira APO, Ueira-Vieira C, PaulinoTP, Soares SC, et al. Antibiotic resistance of bacteria involved in urinary infections in Brazil: a cross-sectional and retrospective study. Int J Environ Res Public Health. 2016;13(9):918. [acesso 2017 Out 10]. DOI: http://dx.doi.org/10.3390/ijerph13090918

36. Guneysel O, Suman E, Ozturk TC. Trimethoprim-sulfamethoxazole resistance and fosfomycin susceptibility rates in uncomplicated urinary tract infections: time to change the antimicrobial preferences. Acta Clin Croat. 2016;55(1):49-57. [acesso 2017 Out 10]. DOI: http://dx.doi. org/10.20471/acc.2016.55.01.8

37. Rossignol L, Vaux S, Maugat S, Blake A, Barlier R, Heym B, et al. Incidence of urinary tract infections and antibiotic resistance in the outpatient setting: a cross sectional study. Infection. 2017;45(1):33-40. [acesso 2017 Out 10]. DOI: http://dx.doi.org/10.1007/s15010016-0910-2

38. van Hecke O, Wang K, Lee JJ, Roberts NW, Butler CC. The implications of antibiotic resistance for patients' recovery from common infections in the community: a systematic review and meta-analysis. Clin Infect Dis. 2017;65(3):371-82. [acesso 2017 Out 10]. DOI: http:// dx.doi.org/10.1093/cid/cix233

39. Federação Brasileira das Associações de Ginecologia e Obstetrícia, Sociedade Brasileira de Infectologia, Sociedade Brasileira de Medicina de Família e Comunidade, Sociedade Brasileira de Nefrologia, Colégio Brasileiro de Radiologia. Infecção urinária não complicada na mulher: diagnóstico. Rev Assoc Med Bras. 2011;57(3):258-61. [acesso 2017 Out 10]. Disponível em: https://doi.org/10.1590/S010442302011000300004

40. Federação Brasileira das Associações de Ginecologia e Obstetrícia, Sociedade Brasileira de Infectologia, Sociedade Brasileira de Medicina de Família e Comunidade, Sociedade Brasileira de Nefrologia. Diretrizes Clínicas na Saúde Suplementar: Infecção urinária não complicada na mulher: tratamento. 2011 [acesso 2017 Out 10]. Disponível em: http://diretrizes.amb.org.br/ans/infeccao_urinaria_naocomplicada_na_mulher-tratamento.pdf

a Universidade Federal de São João del-Rei. Divinópolis, MG, Brasil. v.namaste@gmail.com; lucasnicolasv@gmail.com; nicoleffaragao@gmail.com; ap.otavio@gmail.com; paola.msantos@yahoo.com.br; ph.med9ufsj@yahoo.com.br; thaisbraga_@hotmail.com; debinha.fernandino@gmail.com; gusrocha@ufsj.edu.br (Autor correspondente) 